\title{
Interfacing Video Capture, Editing and Publication in a Tangible Environment
}

\author{
Cati Vaucelle and Hiroshi Ishii \\ MIT Media Laboratory, Tangible Media Group \\ 20, Ames Street, Cambridge MA 02139, USA \\ \{cati, ishii\}@media.mit.edu
}

\begin{abstract}
The paper presents a novel approach to collecting, editing and performing visual and sound clips in real time. The cumbersome process of capturing and editing becomes fluid in the improvisation of a story, and accessible as a way to create a final movie. It is shown how a graphical interface created for video production informs the design of a tangible environment that provides a spontaneous and collaborative approach to video creation, selection and sequencing. Iterative design process, participatory design sessions and workshop observations with 10-12 year old users from Sweden and Ireland are discussed. The limitations of interfacing video capture, editing and publication in a self-contained platform are addressed.
\end{abstract}

Keywords: Tangible User Interface, Video, Authorship, Mobile Technology, Digital Media, Video Jockey, Learning, Children, Collaboration.

\section{Introduction}

Enriching a digital interface with the natural language of physical objects offers an aesthetic experience that is exciting for users to share with one another. This paper presents a framework for designing a tangible platform based on a graphical user interface that we implement for video production. We explore the design of tangible interfaces for supporting inter-personal production of digital media. We synthesize performance and editing to facilitate a flow between improvisation and postproduction of a movie. Our multi-user system is targeted for 10-12 year olds. It integrates different layers of complexity, from digitizing the media and performing a movie, to storyboarding a more complex narrative.

Our research departs from Textable Movie, a graphical user interface we created for video production [41]. Textable Movie reduces the technical difficulties of creating a publishable movie by coupling the performative act of telling a story to editing a final movie. Users create a personal mode of interaction with the system by mapping their own keywords to videos and incorporating new video clips and sound samples to their database. A real time engine responds to the user vocal or written keywords by projecting the corresponding movie clips. A set of parameters affects the movie in real time such as zoom, speed, colors, and loop. The same process is used to assemble final movies. In the framework of computational storytelling, Textable Movie promotes the idea of maker-controlled media and can be contrasted to automatic 
presentation systems. By improvising movie-stories created from their personal video database and by suddenly being projected into someone else's video database during the same story, users can be surprised as they visualize video elements corresponding to a story that they would not have expected. Users make their own inference about the visual discoveries rather than being passive to an artificial system that usually makes the inference for them.

The complexity, power and flexibility of Textable Movie can be seen in how novel projects present themselves through its use. The children's immediate response towards the system made it comparable to a video game. Considering this, we created Textable Game, a variation that more directly extends the concepts of Textable Movie to the realm of video games. With Textable Game, teenagers design their action games, exploration games, and mystery games, using their personal video and audio media. They create their own game strategies, rules and scenarios, and become their own video game producers.

During the course of observations, it became apparent that more fusion between capturing, editing and publishing was necessary. This could allow children to focus their attention on content creation. We started exploring the realm of tangible interfaces. For a revisit of Textable Movie, we coupled mobile technologies to a platform that materializes ideas and retrieves them seamlessly. We explored the concept of tangibility of digital data as a way for children to gather and capture data around the city for later retrieval. In this case, tangible objects become metaphors of the captured elements. We created the Moving Pictures device using mobile technology coupled with tangible objects as metaphors [40].

\section{Prior Work}

\subsection{Tangible User Interaction with Video}

We implement a tangible user interface [33], inspired by the tangible bits concept [17] that combines physical objects to digital data. Digital data covers physical objects in a display space [27]. Previous tangible systems move digital media clips around, arrange digital information physically [19], create multimedia stories [22], offer a token-based access to digital information [16, 38], and explore a direct physical organization of digital video clips using multiple handheld computers [42]. A smaller set of displays can be physically manipulated as a group to interact with digital information and media [23].

Moving Pictures builds upon and contributes to previous research on tangible tools for children $[12,25]$. Much of our research centered around the design of a tangible movie-making machine for children thus complementing previous work on supporting children's fantasy and storytelling [5]. Coupling tangible to video is shown to support collaborative exploration of a video collection [34]. A modified camera can also capture both the child and the video of the child [20].

\subsection{Tangible User Interface for Collaboration}

Tangible User Interfaces are designed to encourage collaboration between children $[2,30]$. Tangible mixing tables enable a performance-oriented approach to media 
construction [21]. In StoryMat, a childhood map invites collaboration between children by telling and acting out stories using props, and listening back to stories of others [5]. With ClearBoard, users draw together digitally while talking to each other [18]. In I/O Brush, children use a paintbrush to gather picturesque information from their surroundings and share them with their peers digitally [31].

Moving Pictures contributes to recent attempts in supporting human-human collaboration with ubiquitous computing [32], especially with research on ubiquitous computing devices for sharing pictures at a distance [37].

\subsection{Tangible User Interface for Authorship}

A broad range of interactive table-tops have been conceived for collaboration. The DiamondTouch table [7] invites multiple users to collaborate at the same time. Yumiko Tanaka's Plable is a traditional looking table with which children build an imaginary world [36]. Designers developed a new concept for movie editing to help children understand the process of editing. It consists of printed movie cards that can be re-arranged in any order. Their bar code is used to identify them on a digital screen [24]. Offering authorship though the interaction with tangible interfaces is rare. It is probably because it requires a flexible interface and a software architecture that takes care of data management. Authorship allows children to become active participants instead of simply observers. Our work builds upon research on physical metaphors of recorded personal stories and points of view [39]. In Flights of Fantasy [6] everyday visitors in a gallery move blocks around a tangible table-top to edit sequences based on icons that represent story elements. Philips Design developed a system that replays visual sequences using tangible objects with a stationary computer for capturing and associating media to objects [28]. While these systems invite for capturing and editing movie segments, none of them propose to edit, perform, publish, or share final edited movies with peers. Moving Pictures contains a videojockey mode for children to perform edited movies and to invite them to revisit their effect on an audience.

\subsection{Tangible User Interface for VideoJockeying}

Derived from disc jockey (DJ), the term VJ was used for the first time at the end of the 70 s. A disc jockey performs pre-sampled sounds in real-time, a video jockey is a live performer of visuals. The mechanism of video jockeying is similar to the mechanism employed by silent film directors in constructing a narrative using visual elements, and later in accompanying these visuals with live music [10]. Robots are also videojockeys when they perform and edit movies in real time. The Filmmaking Robot of Douglas Bagnall edits short films by selecting video footages and taking aesthetic decisions [3].

In Moving Pictures, tangible media containers are integrated into mobile technology. Later, the media containers are assembled on an interactive table for performance. The contribution of Moving Pictures resides in three main functions: 1- video capture with tangible media containers 2- Video editing on an interactive 
table using the tangible media containers and a storyboard ring 3- Video and sound performance on the interactive table.

\section{The Design of Moving Pictures}

We combine form, interaction and function throughout our design process informed by research on rich user interfaces [13]. Our design decisions are coupled with user participation. The users are children age 10-12. Our design methodology is based on evaluation results with Textable Movie. We created a series of low fidelity prototypes expressing our evaluation results from Textable Movie. We explored the needs and preferences of 10-12 year old children regarding group interaction, attitudes and trends that potentially influence their choice of products. We applied a participatory design approach to implement a functional prototype of Moving Pictures [8, 9]. Our first design decisions for a tangible revision of Textable Movie were used as a starting point for the children in our participatory design sessions.

Several moderators from Ireland and Sweden organized design sessions with children as co-partners over a period of 8 months. Four structured groups of children were involved. Group 1, involved in participatory design sessions, evaluated the concept throughout the entire project. Group 2 started participating later on, when a first functional prototype was developed. Groups 3 and 4, located in Sweden and Ireland respectively, were involved in a final evaluation. The final evaluation, with groups 3 and 4, is based on a cross-cultural workshop with users from a local school in Umeå, Sweden, and participants from a workshop on video making in Dublin, Ireland. Children in groups 1, 2 and 3 attended the same school in Sweden. All sessions with group 1 were carried out at the school's after-school club and the children participated voluntarily. Sessions with group 2 were planned within school hours and in agreement with teachers.

During initial sessions we learned about the children's use of video-related hardware and software. This led us to observe the complexity of existing products and notice their effects on children's creativity and group interaction. The Textable Movie system was used as a departure point. Low fidelity prototypes were shown to convey the concept of collaboratively mixing media using tangible tokens on an interactive table. The moderators progressively introduced the movie making process as well as electronic components that are used to create an interactive movie-making device.

Together with the research team, users explored different types of input tools and tested a series of design ideas. Children were introduced to a number of cinematic concepts, such as space, time, continuity, point of view and action-reaction sequences. We developed solutions for a spatial, tangible interface that enables a flexible approach to these expressions. Based on our design sessions with the children as participants, we concluded on a variety of prototypes, including the camera (see Figure 1) and the final editing, mixing and performing table (see Figure 2). Besides the structured participant groups, a number of Swedish children from several local schools tested iterations of the prototype during one-day events. Swedish and Irish children from different communities created movie-stories with their own footage. 

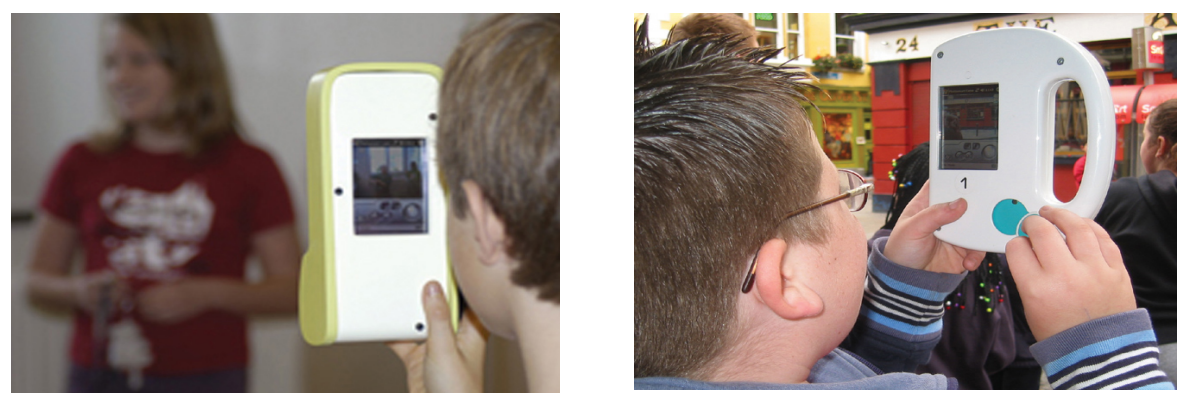

Fig. 1. Camera first prototype vs camera final prototype
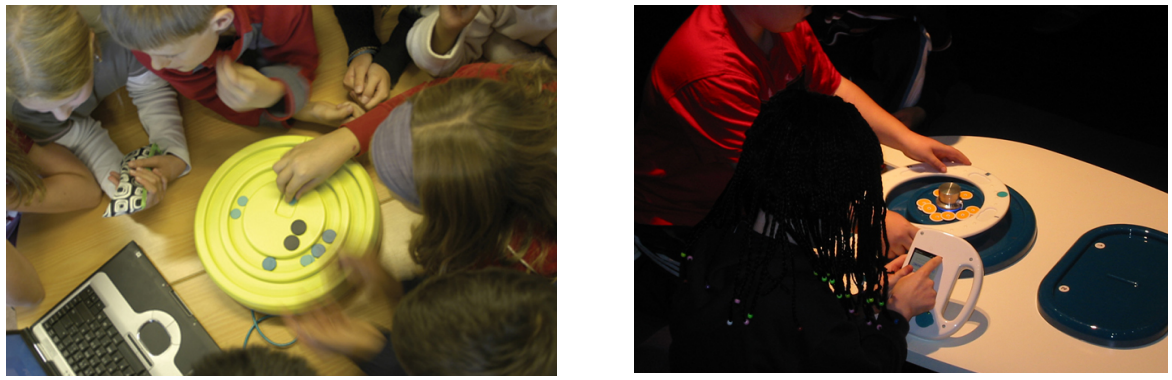

Fig. 2. First prototype of the table vs its final prototype

\subsection{System and Method for Media Editing Using Tangible Media Tokens}

Moving Pictures is a table top with three Radio Frequency Identification (RFID) readers, a laptop computer, a set of speakers, a display, two cameras built into PDAs with RFID capabilities, and a collection of RFID tokens (see Figure 3). Recorded media is associated with digital ID and physical token. Software written for the PDA
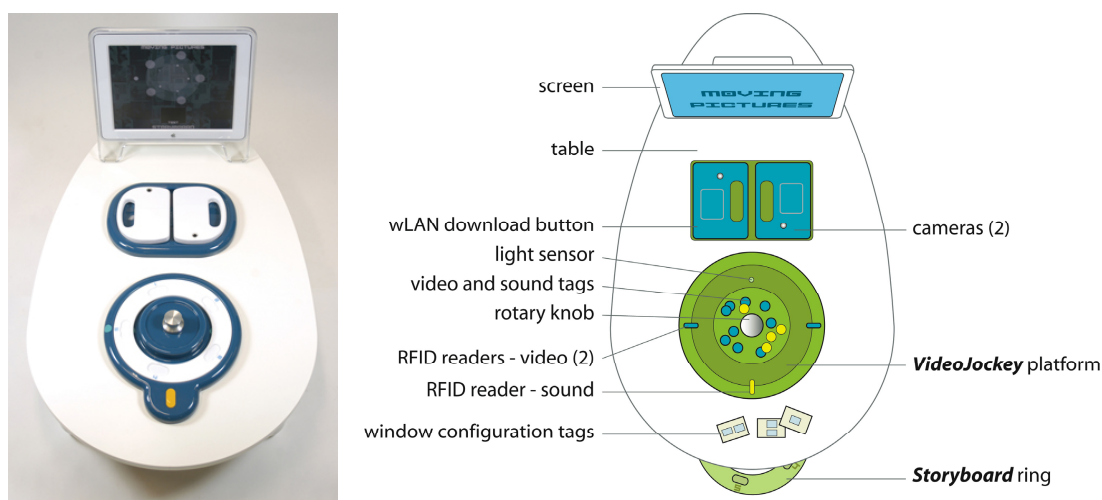

Fig. 3. Moving Pictures 
wirelessly sends the mapped information between token ID and media to the computer as well as the media files themselves. The software written for the computer instantly retrieves the information and plays back the appropriate video or sound segment on a display screen. More specifically, a token with a digital ID is inserted into a PDA that has a camera built into it, so that the token's ID is permanently associated with the temporal sequence of image and sound as it is recorded by the camera. Once removed from the PDA, the physical token can be used to retrieve the sequence of images from memory, to display this sequence and to place this sequence within a longer media sequence. By offering a tangible representation of media elements, Moving Pictures transforms single-user screen-based media sequencing into multi-user physical interaction, adding a collaborative dimension. Moving Pictures incorporates three modes of interaction:

1- Video Capture: Users insert a token in the camera to record a shot.

2- Video Jockeying: Once removed from the camera, the tokens are used as a composition element on the interactive table. Users place the camera on the table and the material collected is transferred to the computer. Users improvise video compositions using the tokens while witnessing at the same time the clips instantaneously being played on the display screen.

3- Video and Sound Editing: Five tokens can be inserted at a time in a personally tailored ring. The rotation of the ring on the table triggers a graphical interface on which the video clips are played instantaneously and sequentially. When the sequence of five video clips, or less, seems satisfying, the children export their final movie on green tokens. These green tokens can themselves be assembled altogether to construct a longer movie. From small clips to longer sequences, children can build up a long and meaningful movie. Sound effects can be applied at any time. In this version of Moving Pictures, sound effects are not edited, but only applied to movie sequences, at a selected point in time. Several aesthetic decisions were made to resemble the DJ's scratching tables. Sounds can overlap with one another, or be individually scratched. Furthermore, the soundtrack is recorded as it is performed.

\subsection{Results from Our Design Process}

Designing a computational object means designing for people. It demands reflecting on the object's critical and aesthetic roles. To this end, researchers propose that designers develop sensitivity to and control of aesthetics, for instance by designing purposeful constraints on communications media [14]. It is within this context that we revisited Textable Movie with specific constraints.

With the use of digital cameras, the technical barriers of producing a final still or moving picture are minimized. The possibility to take risks and experiment is encouraged enabling more expression though the use of visual media. For a majority of the population who do not master the conventions of visual media, some scaffolding, context and constraints may be necessary. Intentionally, in Moving Pictures the user is limited in the length of the captured movie. The tangible metaphor of a token symbolizing a single shot had to be consistent with common motion pictures language. During our evaluation, young adults adopted the physical metaphor accordingly. They were careful with the length of the captured clips. It enabled them 
to practice limited rules in standard video editing without being too conscious of them. Our technical simplification aims to not break the creative flow. We also integrated spatial components in the video cameras to potentially take two points of view on the same scene at the same time. This conveys a sense of space such as closeup and large view on a scene. Users establish an exchange using visuals and sound where capturing and editing is made seamless. The technology is voluntarily not the users' main focus, because we mainly support creative activities generated from organized narratives, visual and spatial movie content. Each object is designed with an individual digital function. For example, the physical storyboard ring controls a graphical storyboard. This ring contains physical tokens and acts as a rotating device to feed the digital storyboard on a computer screen.

To discuss the design of Moving Pictures, we refer to data obtained through participant observations and interviews involving children from groups 1 and 2 as codesigners. Group 1 includes seven 12 year-old girls and group 2 consists of five 11 year-old boys and six 11 year-old girls. The following synthesizes the children's interaction with Moving Pictures [11].

General interaction: Half of the children understood it without instruction.

Confidence in the system: The lack of explanation on what to do with Moving Pictures made the children exchange ideas and explore the system with each other.

The use of the tokens: The children actively used the tokens for data retrieval.

The level of complexity of the interaction: Half of the children retrieved data created by others and the other half mixed their own footage with sound effects.

Our customized cameras versus professional cameras: Children found easy to remember how to interact with them and easy to use. Some children mentioned preferring to use a smaller camera that they can carry in the pocket.

Round shape of the table: Children manifested their preference for a round shaped table to interact with simultaneously as well as to move around. According to the children, a square table would have meant a four user table.

Table size: Children suggested that the table should be smaller if used in a home. However, the table was too small to accommodate more than eight users at a time.

Group Size: In group 2 (22 participants, divided in 2 working sub-groups) some children expressed that the group was too large. Not all participants got a chance to interact during the process of previewing and arranging movies and sounds.

Effectiveness of Group Work: Children recommended the working groups to be smaller, but they also expressed that it was more fun to work in a large group, even though the work was not very effective. In contrast, some children expressed that working in a group made the work easier and more effective, because participants helped each other in generating ideas for movie making.

Agreement vs disagreement: Children pointed out that it could be difficult to work with each other if participants disagree. Many children considered disagreement as being a negative factor in their creative work. They explained how they made efforts in achieving a consensus. They also realized that it was not always possible to keep track of everyone's ideas. 


\section{Evaluation}

We originally created a methodology for international workshops on creative media making and sharing for the Textable Movie project. The workshop engage teenagers from around the world in digital media making using the Textable Movie tool set. The workshop features a design cycle that begins with concept development and continues onto storyboarding, video production, editing and publication on a public display; as it is realized, participants test and evaluate their video-stories using Textable Movie. The workshop global strategy focuses on fostering intercultural visual communication and play. One goal of the international program is to generate a cross-cultural study focused on the creative construction of media by teenagers. The same methodology was used for Moving Pictures, however we included more experts in the language of motion pictures to help us guide and moderate the workshop.

\subsection{Roles Assumed by the Children While Designing and Using Moving Pictures}

In all sessions, children were free to choose their role in the film-making activity. Driven by their personal interests, they chose to be film script-writers, director, actors, camera-men, or scenographers. Children and moderators discussed and clarified the tasks for each role during the sessions. Most children chose the same role repeatedly. When asked if they thought there should be a leader in the group, children had different opinions. Some appreciated not having a leader and being able to have equal participation. Others said they thought it would be better to have a child taking the leading role.

Several children thought that group members had different skills and this could allow them to learn from each other. During the sessions it was obvious the children influenced and learned from each other. For example children sometimes helped each other by explaining and showing one another how to perform different tasks. Piaget describes how children influence one another in different ways and how when it happens is of great importance for a child [4]. The children often changed opinions during the sessions, influenced by their friends. This might be a sign of a close collaboration. Prior research shows that when working on film-making, children learned a great deal from each other [9].

As time passed, children became more accustomed to the technologies used in the design sessions and behaved more spontaneously and independently around them. Some children chose to spend much time arranging video clips and adding corresponding sounds to them, eventually becoming "experts" at this task. Others "specialized" in their acting skills or in camera techniques.

\subsection{Creativity and Learning}

Observing the creativity process of the children working on digital media with Moving Pictures, we reflected on the four aspects of student Understanding of the Arts proposed by Ross [29] and reintroduced by Somers [35]: Conventionalisation an awareness and ability to use the conventions of the art form, Appropriation embracing, for personal use, the available expressive forms, Transformation - in which the student searches for knowledge and meaning through the expression of 
'feeling impulses', and Publication - the placing of the result in the public domain. Using Moving Pictures, children understood the process of making a movie using a series of traditional shots symbolized by physical tokens. They made a movie respecting the collaborative storyboard they created. They contributed to a multinational visual database by expressing their visual narratives for children living in another country.

\subsection{Results from the Process of Capturing a Movie to Projecting it}

Through the course of the evaluation, Irish children created a series of movies. Children chose and selected the different themes. The choices varied from: journalistic interviews that were limited to five shots, explorations in the city using more than ten shots, five individual shots of the children acting in front of their favorite city place, a more sophisticated five-shot criminal story with a beginning, a middle, and an end, and a theater play using ten shots. The most popular edited movies are the individual shots of the children and the sophisticated criminal story. We analyzed the two most popular movies to understand how the interfacing of video capture, editing and publication were optimally taken advantage of in our tangible environment (see the Table bellow).

\begin{tabular}{|c|c|c|}
\hline & Individual shots & The story \\
\hline Paper storyboard / planning & $\begin{array}{l}\text { No storyboard. The } \\
\text { children had in mind their } \\
\text { favorite place they wanted } \\
\text { to be videotaped in front of. }\end{array}$ & $\begin{array}{l}\text { Children spent an hour } \\
\text { planning their story, } \\
\text { storyboarding and looking } \\
\text { for the right spot. }\end{array}$ \\
\hline $\begin{array}{l}\text { Video Capture / process of } \\
\text { revisiting/erasing shots }\end{array}$ & $\begin{array}{l}\text { One child revisited the way } \\
\text { to jump from one side to } \\
\text { the other side of the frame } \\
\text { to create continuity within } \\
\text { the final movie. His peers } \\
\text { were part of his exploration } \\
\text { and repeated the same idea. }\end{array}$ & $\begin{array}{l}\text { The shots were constantly } \\
\text { revisited, erased and } \\
\text { accumulated. Children } \\
\text { labeled the token to have } \\
\text { the choice of different shots } \\
\text { for the same segment of the } \\
\text { story. }\end{array}$ \\
\hline Visualizing briefly the shots & $\begin{array}{l}\text { All of the shots were pre- } \\
\text { visualized and organized. }\end{array}$ & $\begin{array}{l}\text { All of them were visualized } \\
\text { and organized. }\end{array}$ \\
\hline $\begin{array}{l}\text { Editing using the storyboard } \\
\text { ring on the table }\end{array}$ & $\begin{array}{l}\text { No editing of the sequences } \\
\text { seemed necessary. Children } \\
\text { used their appearance order } \\
\text { when they started shooting. }\end{array}$ & $\begin{array}{l}\text { Children enjoyed different } \\
\text { outcomes using the same } \\
\text { shots. They end up } \\
\text { selecting three final movies. }\end{array}$ \\
\hline $\begin{array}{l}\text { Editing a soundtrack using } \\
\text { the respective yellow tokens }\end{array}$ & $\begin{array}{l}\text { One specific sound per } \\
\text { location. Children did not } \\
\text { choose to perform complex } \\
\text { sound mix, but carefully } \\
\text { chose their sounds. }\end{array}$ & $\begin{array}{l}\text { Children performed a } \\
\text { complex sound mix, } \\
\text { overlapping sounds and } \\
\text { creating continuity within } \\
\text { the soundtrack. }\end{array}$ \\
\hline Publication $a$ & $\begin{array}{l}\text { Children did not try various } \\
\text { movies out of the shots, } \\
\text { only performed a final } \\
\text { movie. }\end{array}$ & $\begin{array}{l}\text { Children kept three favorite } \\
\text { movies for videojockeying. }\end{array}$ \\
\hline
\end{tabular}


The students did not want to edit the other country's final movies. Instead, they were excited to watch the variations in the movies and to continue them. This shows potential for cultural exchange through video making.

\subsection{Discussion}

The tangible integration of a video production process allows anyone to revisit the footage. It presents benefits in improvising and performing movies collaboratively. The shape of the table specifically invites children to collaborate with each other. Videojockeying is a spontaneous way to perform final pieces and to integrate selected sounds. Children were engaged and attentive in the production of all the video-stories they created. They considerably focused on the content and were comfortable with the technology. They preferred two of their creations: the individual shots movie consisting of sequences of children jumping in different parts of a city - and the sophisticated criminal story in the center of Dublin. We noticed that the most complex features of Moving Pictures were used while editing the sophisticated story.

Reducing the complexity in personal production of digital media and interfacing the process of capturing, editing and performing allows children to experiment effectively with movie sequences.

Even though the system is not empirically compared with commercialized video editing tools, we did prior user testing with iMovie. We chose iMovie as we found it an easy tool to edit movies. In this study, the children were from the same community as the students who participated in the workshop presented in this paper. Almost all the children were impatiently waiting for their movies to be digitalized in iMovie. Some gave up on their original objectives. Other children kept capturing with the professional video camera not wanting to edit anything. When editing, children wanted a final movie almost instantly and were confused when they had to erase parts of their movies. For this reason Moving pictures uses raw data captured in small clips. This functionality in our system seemed to work better for the children. Having the digital data represented by a physical object helped them understand the construction of their movies. At no time they were bored or overwhelmed. One main complaint was that the number of the shots possible to take at one time was too small. They also asked for the ability to incorporate their own sound effects. As it is, Moving Pictures only offers the recording of sounds with the video. With iMovie, children never experimented using different endings with their video footages. In our evaluation with Moving Pictures, children captured and revisited their video story elements, edited and experimented with various positions of their shots within the story and this even if the number of shots was only five for the story. With Moving Pictures, children created a soundtrack using sound mixed together.

In early sessions, children asked each other and test leaders for help as soon as they did not understand the instructions. The lack of instructions seemed to be a way to get to know each other better. Research shows that students at various performance levels, working together toward a common goal, can enhance each other's analysis, synthesis, and evaluation of the concepts they are exploring [15]. However, Ackermann [1] explains that changing perspectives and switching roles requires the difficult balance between being simultaneously immersed and disengaged. We studied how people engage in relationships where they exchange their perspectives and 
transfer a sense of space through play, collaboration, and storytelling using dynamic media containers and tangible media interfaces. During our observations, we found that even though generally children in the same group age have a similar cognitive development, it is important to design systems that are flexible enough to accommodate individual characteristics.

\section{Limitations}

Based on our evaluations with children, we found that Moving Pictures suffers from several limitations related to the problem of how to best digitally support meaningful interactions in the physical space and interfacing video capture, editing and publication in a tangible environment. First the scalability of such a system at a networked and international level is flawed. We need to redesign the software technology to centralize the linked data and distribute the nodes of contained data in an organized fashion. To have the technology better assist how an individual moves about the physical space while capturing content, their platform needs to be mediated by a centralized software architecture.

Second, system centralization implies new communication technology to mediate the video platforms and allow them to communicate with one another. The RFID technology in the wireless cameras could be redesigned into a pattern based technology using the video camera of any device.

Lastly, we would like to escape the hardware limitations of commercial video cameras. Users could use any phone, any camera or text based device to exchange material. The system should be designed to generalize despite different input modalities. All of these modifications shift the emphasis of the system from a simple, transparent, video platform, and into an architecture for supporting content generation that reflects the physical environment of the user through multiple information platforms.

\section{Conclusion and Future Work}

In a world in which media is everywhere, individual and collaborative media creation can provide a means of exploring our environment. Technology can bring people together, even if they have never met before. Our research trajectory is to understand interfaces that empower people in expressing and sharing ideas about their social environment, actively "constructing" personal content. Constructionists suggest that users benefit from systems that support self-expression rather than systems that create content for the user. Papert proposes that systems for children can relate to their 'realworld' experiences to learn specific skills such as mathematics [26].

Movie editing systems support personal creations and offer the opportunity for one to reflect on 'real world' experiences. Authorship is enhanced if the assembly of the movie is made out of elements in a story that can be explored and combined in real time. "Children build, make or manipulate objects or artifacts and in doing so are confronted with the results of their actions, learning as they go" [26]. In Moving Pictures, the children create the content of their stories that can be used for performance and editing, and they also learn the process of making a movie "as they go". 
The ultimate goal of this research is to interface video capture, video editing and video publication in a self-contained platform. In addition to identifying limitations, we have also shown the changes that need to take place for the improvement of this, and similar systems. During the design and evaluation sessions, we noticed that Moving Pictures helps to engage smaller groups of children in one task - moviemaking. Even though it allows users to participate in different activities, the level of participation depends on individual initiative. It would therefore be interesting to use multi-user systems in a learning environment, for instance within the school's curriculum. With Moving Pictures anyone could test movie scenarios by capturing quickly a few shots and assembling a quick movie draft. Future work will include improvisational theatre sessions organized using the wireless video camera as an expressive tool and the video jockey table as an instant review display of the improvisation to assemble a collaborative video. Throughout the workshops with the children we collected valuable data for future iterations. At times, we observed how children interact with the system in unexpected ways, which has inspired us to explore new functionality and to improve existing features. The empirical evaluation of children's analysis of their personal work as well as children's analysis of the work of other students in remote locations must be left for future work.

Acknowledgments. We would like to thank the Media Lab Europe for supporting the implementation of Textable Movie and Moving Pictures. Glorianna Davenport for advising this research from 2002-2005. Diana Africano and Oskar Fjellström for our collaborative research on Moving Pictures in 2004 at the Umeå Institute of Design in Sweden, Joakim Sällberg for the model making of Moving Pictures and Jenny Fredriksson for co-observing the participatory design sessions in Sweden. Michael John Gorman, Leo Mc Kenna, the Ark in Dublin, Vincent Le Bail, Eoghan Kidney, the School of Ostermalm who participated in our evaluations. Diana Africano, Adam Boulanger and the conference reviewers for their feedback on the paper. The tangible media group - past and present members - for their valuable input and The MIT Media Lab community.

\section{References}

1. Ackermann, E.K.: A learning zone of one's own: Sharing representations and flow in collaborative learning environments. In: Tokoro, M., Steels, L. (eds.), Amsterdam, Berlin, Oxford, Tokyo, Washington, DC, Part 1. Ch. 2, pp. 15-37. IOS Press, Amsterdam (2004)

2. Africano, D., Berg, S., Lindbergh, K., Lundholm, P., Nilbrink, F., Persson, A.: Designing tangible interfaces for children's collaboration. In: CHI '04 Extended Abstracts on Human Factors in Computing Systems, pp. 853-868. ACM Press, New York (2004)

3. Bagnall, D.: The Filmmaking Robot (2006), http://www.halo.gen.nz/robot/

4. Bukowski, W.M., Newcomb, A.F., Hartup, W.W.: The company they keep: Friendship in childhood and adolescence. Cambridge University Press, New York (1996)

5. Cassell, J., Ryokai, K.: Making Space for Voice: Technologies to Support Children's Fantasy and Storytellin. Personal Technologies 5(3), 203-224 (2001)

6. Davenport, G.: Flights of Fantasy (2001), http://www.decordova.org/decordova/exhibit/ flights.htm 
7. Dietz, P., Leigh, D.: DiamondTouch: a multi-user touch technology. In: Proceedings of the 14th Annual ACM Symposium on User interface Software and Technology. UIST '01, pp. 219-226. ACM Press, New York (2001)

8. Douglas, S., Aki, N.: Participatory Design: Principles and Practices. Lawrence Erlbaum, Mahwah (1993)

9. Druin, A., Bederson, B., Boltman, A., Miura, A., Knotts-Callahan, D., Platt, M.: Children as our Technology Design Partners. In: Druin (ed.) The Design of Children's Technology, pp. 51-72. Morgan Kaufmann Publishers, San Francisco (1999)

10. Faulkner, M.: D-Fuse - VJ, Audio-visual Art and VJ Culture. Laurence King Publishing (2006)

11. Fredriksson, J.: Children's Collaboration when Interacting with a Multi-User System. Master Thesis in Cognitive Science. Umeå University (2006)

12. Frei, P., Su, V., Mikhak, B., Ishii, H.: Curlybot: designing a new class of computational toys. In: Proceedings of the SIGCHI Conference on Human Factors in Computing Systems. CHI '00, pp. 129-136. ACM Press, New York (2000)

13. Frens, J.W., Djajadiningrat, J.P., Overbeeke, C.J.: Rich Interaction: issues. Ambient Intelligence. In: Markopoulos, P., Eggen, B., Aarts, E., Crowley, J.L. (eds.) EUSAI 2004. LNCS, vol. 3295, pp. 271-278. Springer, Heidelberg (2004)

14. Gaver, B.: Provocative Awareness. Computer Supported Cooperative Work 11(3), 475493 (2002)

15. Gokhale, A.A.: Collaborative Learning Enhances Critical Thinking. Journal of Technology Education 7(1) (1995)

16. Holmquist, L.E., Redström, J., Ljungstrand, P.: Token-Based Access to Digital Information in Lecture Notes in Computer Science, p. 234. Springer, Heidelberg (1999)

17. Ishii, H., Ullmer, B.: Tangible bits: towards seamless interfaces between people, bits and atoms. In: Pemberton, S. (ed.) CHI '97. Proceedings of the SIGCHI Conference on Human Factors in Computing Systems, pp. 234-241. ACM Press, New York (1997)

18. Ishii, H., Kobayashi, M.: ClearBoard: a seamless medium for shared drawing and conversation with eye contact. In: Bauersfeld, P., Bennett, J., Lynch, G. (eds.) Proceedings of the SIGCHI Conference on Human Factors in Computing Systems. CHI '92, pp. 525 532. ACM Press, New York (1992)

19. Jacob, R.J., Ishii, H., Pangaro, G., Patten, J.: A tangible interface for organizing information using a grid. In: Proceedings of the SIGCHI Conference on Human Factors in Computing Systems: Changing Our World, Changing Ourselves. CHI '02, pp. 339-346. ACM Press, New York (2002)

20. Labrune, J., Mackay, W.: Tangicam: exploring observation tools for children. In: Proceeding of the 2005 Conference on interaction Design and Children. IDC '05, pp. 95102. ACM Press, New York (2005)

21. Lew, M.: Live cinema: an instrument for cinema editing as a live performance. In: Barzel, R. (ed.) ACM SIGGRAPH 2004 Sketches. SIGGRAPH '04, p. 117. ACM Press, New York (2004)

22. Mazalek, A., Davenport, G.: A tangible platform for documenting experiences and sharing multimedia stories. In: Proceedings of the 2003 ACM SIGMM Workshop on Experiential Telepresence. ETP '03, pp. 105-109. ACM Press, New York (2003)

23. Merrill, D., Kalanithi, J., Maes, P.: Siftables: towards sensor network user interfaces. In: Proceedings of the 1st international Conference on Tangible and Embedded interaction. TEI '07, pp. 75-78. ACM Press, New York (2007)

24. Miyabara, M., Sugimoto, T.: Movie Cards (2006), http://www.videologue.com/ 
25. Montemayor, J., Druin, A., Chipman, G., Farber, A., Guha, M.: Storyrooms and playsets: Tools for children to create physical interactive storyrooms. Computers in Entertainment 2(1) (2004)

26. Papert, S., Harel, I.: Constructionism. Ablex Publishing Corporation, NJ (1991)

27. Patten, J., Ishii, H., Hines, J., Pangaro, G.: Sensetable: a wireless object tracking platform for tangible user interfaces. In: Proceedings of the SIGCHI Conference on Human Factors in Computing Systems. CHI '01, pp. 253-260. ACM Press, New York (2001)

28. Rizzo, A., Marti, P., Decortis, F., Rutgers, J., Thursfield, P.: Building narratives experiences for children through real time media manipulation: POGOworld. In: Blythe, M.A., Monk, A.F., Overbeeke, K., Wright, P.C. (eds.) Funology: from usability to enjoyment (1-12), Kluwer Academic Publisher, Amsterdam (2003)

29. Ross, M., Radnor, H., Mitchell, S., Bierton, C.: Assessing Achievement in the Arts. Open Univ. Press, Stony Stratford, England (1993)

30. Ryokai, K., Vaucelle, C., Cassell, J.: Virtual Peers as Partners in Storytelling and Literacy Learning. Journal of Computer Assisted Learning 19(2), 195-208 (2003)

31. Ryokai, K., Marti, S., Ishii, H.: I/O brush: drawing with everyday objects as ink. In: Proceedings of the SIGCHI Conference on Human Factors in Computing Systems. CHI '04, pp. 303-310. ACM Press, New York (2004)

32. Salvador, T., Barile, S., Sherry, J.: Ubiquitous computing design principles: supporting human-human and human-computer transactions. In: CHI '04 Extended Abstracts on Human Factors in Computing Systems. CHI '04, pp. 1497-1500. ACM Press, New York (2004)

33. Sharlin, E., Watson, B., Kitamura, Y., Kishino, F., Itoh, Y.: On tangible user interfaces, humans and spatiality. Personal and Ubiquitous Computing 8(5) (2004)

34. Sokoler, T., Edeholt, H.: Physically embodied video snippets supporting collaborative exploration of video material during design sessions. In: Proceedings of the Second Nordic Conference on Human-Computer interaction. NordiCHI '02, vol. 31, pp. 139-148. ACM Press, New York (2002)

35. Somers, J.: Measuring the shadow or knowing the bird. Evaluation and assessment of drama in education. In: Sefton-Green, J., Sinker, R. (eds.) Evaluating creativity. Making and Learning by Young People, pp. 107-128. Routledge, London (2000)

36. Tanaka, Y.: Plable (2006), http://yumikotanaka.net/

37. Truong, K.N., Richter, H., Hayes, G.R., Abowd, G.D.: Devices for sharing thoughts and affection at a distance. In: CHI '04 Extended Abstracts on Human Factors in Computing Systems. CHI '04, pp. 1203-1206. ACM Press, New York (2004)

38. Ullmer, B., Ishii, H.: Emerging frameworks for tangible user interfaces. IBM Journal (2000)

39. Vaucelle, C., Jehan, T.: Dolltalk: a computational toy to enhance children's creativity. In: CHI '02 Extended Abstracts on Human Factors in Computing Systems. CHI '02, pp. 776777. ACM Press, New York (2002)

40. Vaucelle, C., Africano, D., Davenport, G., Wiberg, M., Fjellstrom, O.: Moving pictures: looking out/looking in. In: Beckmann-Wells, P. (ed.) ACM SIGGRAPH 2005 Educators Program. SIGGRAPH '05, pp. 27-34. ACM Press, New York (2005)

41. Vaucelle, C., Davenport, G.: A System to Compose Movies for Cross-Cultural Storytelling: Textable Movie. In: Göbel, S., Spierling, U., Hoffmann, A., Iurgel, I., Schneider, O., Dechau, J., Feix, A. (eds.) TIDSE 2004. LNCS, vol. 3105, pp. 126-131. Springer, Heidelberg (2004)

42. Zigelbaum, J., Horn, M.S., Shaer, O., Jacob, R.J.: The tangible video editor: collaborative video editing with active tokens. In: Proceedings of the 1st international Conference on Tangible and Embedded interaction. TEI '07, pp. 43-46. ACM Press, New York (2007) 